\title{
An illustrated step-by-step guide to establish a disinfection facility for reuse of personal protective equipment
}

\section{Vikram Saini ( $\nabla$ vikram@aiims.edu )}

Department of Biotechnology, All India Institute of Medical Sciences, New Delhi-110029, India, and Biosafety Laboratory-3, Centralized Core Research Facility (CCRF), All India Institute of Medical Sciences, New Delhi-110029, India https://orcid.org/0000-0002-0258-2871

\section{Priya Kalra}

Department of Biotechnology, All India Institute of Medical Sciences, New Delhi-110029, India

\section{Method Article}

Keywords: Personal Protective Equipment (PPE), Disinfection facility, COVID-19, biosafety, vapourized hydrogen peroxide (VHP)

Posted Date: August 20th, 2020

DOI: https://doi.org/10.21203/rs.3.pex-1082/v1

License: (c) (i) This work is licensed under a Creative Commons Attribution 4.0 International License. Read Full License 


\section{Abstract}

COVID-19 pandemic has created unforeseen public health challenges including the disruption of a steady supply of personal protective equipment (PPE) for health care workers (HCWs). Several approaches have been evaluated for safe disinfection of used PPEs to allow their selective reuse. We have recently shown that Vaporized Hydrogen Peroxide (VHP) is a safe, easy-to-scale up, economical and environment friendly method to disinfect PPE (coveralls, N-95 masks and face-shields) without compromising their quality and integrity even after repeated cycles of disinfection (Saini et al., 2020). Based on this method, we have operationalized a PPE disinfection research facility at All India Institute of Medical Sciences (AIIMS), New Delhi, a tertiary care medical centre in India. Considering the immense potential of this approach, we have been repeatedly approached by various hospitals to provide a detailed standard operating guideline to run such a facility. Herein, we present a step-by-step illustrative guide that we believe would be helpful to operationalize a PPE disinfection facility at health care settings. This guide incorporates elements and steps of biosafety necessary to handle used PPE during COVID-19 settings and can be adapted for various methods of PPE disinfection, and various pathogens.

\section{Introduction}

During pandemic events, worldwide efforts are prioritized to provide a steady supply of personal protective equipment (PPE), especially to the front-line responders. There is a massive surge in PPE demand leading to increased prices adding to the cost of diagnostics and treatment. Further, the singleuse of PPE generates serious problem of biomedical waste and poses significant environmental threat. Novel approaches are required to circumvent these challenges. PPE reuse post-disinfection is an economically viable and environment friendly method (Saini et al., 2020). In this context, developing safe and effective ways of disinfection for reuse of PPE has been an active area of research and scientists have good success in developing several effective approaches (Viscusi et al., 2009; Bergman et al., 2010; Heimbuch et al., 2011; Polkinghorne and Branley, 2020; Saini et al., 2020). Different regulatory authorities such as US FDA and Occupational Safety and Health Administration (OSHA, 2007) have made recommendations to allow the PPE reuse during emergency situations if (i) these used PPE are not heavily soiled or physically damaged, (ii) are reliably disinfected with a certified and safe disinfection method, and (iii) retain their original functionality.

With respect to the disinfection, various methods are available that has been evaluated in different settings to inactivate wide range of pathogens, including SARS-CoV-2, the causative organism of the current COVID-19 pandemic. Amongst these, the Centers for Disease Control and Prevention (CDC) lists ultraviolent germicidal irradiation (UVGI), moist heat and vaporized hydrogen peroxide (VHP) as the most promising PPE disinfection methods (CDC COVID-19 report, 2020; Polkinghorne and Branley, 2020). Unfortunately, though despite the availability, the utility of these methods in part is limited by lack of practical knowledge and know how about various aspects required to set-up the disinfection facility. This is especially true in the clinical settings where infection control units are already heavily burdened and grappling with COVID-19. 
We have recently shown that VHP-based disinfection is an effective solution for safe disinfection and reuse of not only N-95 masks, but also for coveralls, face shields etc. (Saini et al., 2020). Encouraged by our findings, we have successfully established a VHP Disinfection Facility at the All India Institute of Medical Sciences (AlIMS), New Delhi, India, a tertiary care hospital and designated National nodal center for COVID-19. So far, we have disinfected more than 3000 PPE coveralls and masks for reuse. Promising implications of this approach has attracted the attention of various health care centres requesting us to provide a sufficiently detailed instructions to operationalize similar facilities. This has prompted us to develop a step by step graphically enriched guide on operationalizing a safe and biosafety compliant (Rutala and Weber, 2008) PPE Disinfection Facility. The guidelines presented here are fairly broad-based and are adaptable to any PPE disinfection methodology.

In this guide, we first show a flow-chart to establish a biosafety compliant PPE disinfection facility

(Fig. 1). This whole set-up must include: (i) an established work-flow to segregate and manage used PPE, (ii) Biosafety compliant transportation of used PPE, (iii) Designated area for storage of used PPE and disinfection, (iv) Developing efficient protocols for the disinfection of PPE (Coverall, Goggles, Faceshields, and N-95 Masks), and (v) Storage and Supply of clean PPE post-disinfection.

\section{Reagents}

Hospital supplies of PPE for healthcare workers (Table 1), hydrogen peroxide stock solution (11 - 12\%) stabilized with silver nitrate $(0.01 \%)$, biological indicator strips coated with $10^{6}$ spores of $B$. stearothermophilus spores (Sigma Aldrich, USA), laboratory grade ethanol, hypochlorite, distilled water, Brain Heart Infusion (BHI) media (HiMedia Laboratories, India), biomedical waste collection bags, bins and carriers.

\section{Equipment}

Vaporized hydrogen peroxide generator (SATEJ Plus machine, Ahmedabad, India) and a dedicated Microbiology culture facility.

\section{Procedure}

\section{Step 1: Segregation of recyclable used PPE}

We recommend segregation of used PPE by the users at the doffing site itself as per the respective institutional biomedical waste management guidelines. Based on the cultural and social practices, acceptability of disinfected PPE for reuse may vary in different settings. Considering these things in mind, it is a good idea to sensitize the potential users about benefits of reusability and allow them to decide whether they want to send the used PPE to trash or the recycle bin at the time of doffing. We recommend to have an illustrative guide for PPE segregation at the doffing site, displayed in an easy-to-understand 
format of posters (Fig. 2) or pictures including in the native/vernacular language. Basic guiding principles to keep or discard the PPE should be provided as listed below:

1) Used PPE that are weakened in strength, torn, soaking-wet or heavily soiled in patients' body fluids are not suitable for recycling. Such PPE should be identified during doffing and discarded as per the institutional guidelines (Fig. 2a).

2) Used PPE that are intact or have minor stains are suitable for reuse post-disinfection and should be placed in a designated "Used PPE" biohazard bin during doffing (Fig. 2b).

\section{Step 2: Collection and transport of used PPE for Disinfection}

1) After the collection of recyclable used PPE in designated bins (from Fig. 2b), a healthcare worker (HCW) donned in complete PPE gear should bag the used PPE, wipe the bag with $0.5 \%$ hypochlorite on the outside, double bag it and wipe the outside bag with $0.5 \%$ hypochlorite once again (Fig. 3a).

2) These bags will be transported one-by-one to the door, and should be handed over to another HCW, standing outside for further transportation (Fig. 3b).

Note: HCWs must be donned in proper PPE gear (refer to Table 1 for proper PPE) while handling the used PPE bags. It is important that the used PPE bags are handled strictly as per the institutional guidelines.

3) If the designated PPE Disinfection Facility is within the hospital premises or nearby, the HCW may collect the used PPE bags in a designated trolley (that has a lid for closing), and transport them to the PPE Disinfection facility (Fig. 3c).

4) If the designated PPE Disinfection Facility is present at a distance or outside the hospital premises, the used PPE bags should be first collected into cardboard boxes, and sealed properly prior to transport to the PPE Disinfection Facility by a dedicated Biomedical waste vehicle (Fig. 3d).

Note: Ideally, the PPE collection, and disinfection areas should be in close vicinity, in an isolated or less visited site, preferably near to the areas generating maximum used PPE. The physical proximity will significantly minimize the biosafety risk associated with the transportation.

\section{Step 3: Receiving of used PPE bags at the PPE Disinfection Facility}

A proposed PPE Disinfection Facility should ideally be constructed at an isolated area, and should be designed to have dedicated rooms for donning, doffing, bag storage area, PPE Disinfection area and Post-disinfection quality check area and Post-disinfection storage of used PPE. The size of the storage 
and disinfection rooms in the facility should be proportionate to the PPE utilization capacity of the healthcare institution.

1) The Used PPE bags (from Fig. $\mathbf{3 c}$ and/or $\mathbf{3 d}$ ) should be received at the entrance of the PPE Disinfection Facility by a dedicated HCW and carried to the storage area (Fig. 4a).

\section{Features of storage area:}

a. Preferably the storage room should have cubicle-type partitions (5 - 8 feet) such that a clear area of at least 3 - 4' is left from the wall to ensure free movement of man and material (Fig. 4 b).

b. The Used PPE storage area should have ample space to hold PPE for at least 3-5 days. Since the SARS-COV-2, the etiological agent of COVID-19, has a variable survival on various surfaces, storage of used PPE will allow a natural reduction of viral load (Kampf et al., 2020), further minimizing the biohazard for the workers operating the facility.

c. These cubicle areas should be numerically labelled for ease of record keeping and would hold the double bagged used PPE which may include coveralls, face-shields, goggles, N-95 masks etc.

d. Each cubicle should have a clear signage (Fig. 4) of date of receiving and processing due date.

Note: It is crucial for the Facility to maintain a consistent record and cataloguing of each batch of Used PPE bags. The access to the facility should be tightly regulated and if possible, should be monitored using CCTV cameras.

\section{Step 4: Transport of used PPE from storage area to the Disinfection area}

From the PPE collection area, the bags would be transported to the disinfection area as per the biosafety compliance work-flow. The below mentioned work-flow is tailored for a VHP-based disinfection facility but most of the precautions listed here are universally applicable intendent of method of disinfection.

\section{Features of PPE Disinfection area:}

a. The area designated as such should be closer to the collection area, and should have electrical supply preferably with a UPS/generator back-up to run the VHP machine.

b. The VHP machine requires making dilutions with distil water, so access to distil/autoclaved water, measuring cylinders, and other accessories for hand hygiene of the person operating the machine should be provided.

c. The room should be air-tight to the extent possible to ensure proper exposure time to PPEs Since the disinfection process is dependent on achieving a minimum vapour concentration with sufficient contact 
time, any leakage may compromise the disinfection process.

d. The room size should be compatible with the capacity of the VHP machine. In our hands, even though capacity of the machine was high, a room size of less than $3500 \mathrm{cu} \mathrm{ft}$. worked the best due to practical difficulty to control vapour leak in larger rooms in our settings.

e. The VHP room should preferably have two independent doors, which can be dedicatedly used to establish a biosafety compliant workflow - One door for transferring the bags containing used PPES, while another one with access towards the clean area exclusively to allow a smooth collection of the sterilized PPEs after the disinfection cycle.

f. The room door should preferably have a glass pane to allow inside view without the need of opening the door. Having a small glass pane is very useful as one can instruct by gesture or also carry out visual inspection whether all the vapours are cleared once the process is over.

g. The room should have appropriate air-conditioning to keep the ambient temperature inside. And the area should have access control options, either manually or automatically with proper entry and exit records.

h. The disinfection room would have a stepper, gloves, disinfectant solution, and ready to use VHP machine inside. Additional items such as small tables etc. may be kept based on requirements.

\section{Step 4.1: Receiving used PPE bags in Disinfection area}

1) The HCW wearing appropriate PPE (Table 1) will transport the used PPE bags to the gate of the VHP disinfection room by using a dedicated wheel cart/trolley (Fig. 5a).

2) The HCW will first carry out the required number of bags inside the room and keep them close to the door (Fig. 5b).

3) Prior to opening the Used PPE bags, the HCW must manually program the VHP machine as per the room dimensions (length $\times$ width $\times$ height in feet) and adding the required volume of hydrogen peroxide solution (please refer to Table 2, Step 5). This programming is a onetime requirement that should be done prior to the very first disinfection run (in our hands, 2000 cu feet rooms requires $\sim 650 \mathrm{ml}$ of $6-8 \%$ stabilized $\mathrm{H}_{2} \mathrm{O}_{2}$ ).

Note: The vaporizer should be placed on a stable and firm surface such that should not be any obstruction in front of the machine nozzle for at least 3 feet at a $45^{\circ}$ angle.

\section{Step 4.2: Arranging used PPE in the disinfection room}


4) The bags should be opened individually to take out the inner bag. This inner bag should be carried towards the end of the room as indicated in Fig. 6a.

5) The HCW should carefully take out the used PPE coveralls one-by-one, and straightened without folds, exposing the outer surface, zip open and keeping the front side of the used PPE away from the HCW's face (Fig. 6b).

Note: The coveralls should be hung on hangers (hangers may be kept in a bucket having freshly prepared $1 \%$ hypochlorite solution prior to use) onto the cloth lines such that it is at least 6 inches above floor, 6 inches away from the side walls and 6 inches below ceiling, with 1-foot distance between two coveralls on a line and at least a 2 feet distance between the two rows. This is to ensure efficient diffusion of vapours during the disinfection process.

6) Used N-95 masks should be aligned on grilled wire racks (Fig. 7a) and used face shields to be arranged on table surface (Fig. 7b). If powered air purifying respirators (PAPR) are to be disinfected, they can also be hanged with cloth lines to allow complete exposure.

7) To ensure quality assurance for each disinfection run, we recommend keeping minimum of two Biological Indicator strips (e.g. Bacillus stearothermophilus spores) on the used PPE at the corners of the room farthest from the machine, for quality assurance (Fig. 7c).

\section{Step 5: Running of the disinfection cycle: VHP machine}

1) The user must adhere to the manufacturer's instructions to operate the VHP machine.

2) Briefly, once the machine is properly set-up, press the start button and, exit the room through the door towards dirty area and seal the door from the outside. Almost all VHP machines have a provision for a lag period (30 sec to $1 \mathrm{~min}$ ) to allow the HCW to exit the room prior to peroxide vapour generation.

3) Upon exit, the HCW must seal the room door from the outside.

4) The room size, run time, capacity to disinfect PPE and amount of peroxide required in our hands are listed below (Table 2):

Note: Hydrogen peroxide used in the disinfection process should be stabilized with a chemical agent. We have used a stock solution of $11-12 \% \mathrm{H}_{2} \mathrm{O}_{2}$ stabilized with $0.01 \%$ silver nitrate in our experiments.

5) Post-run, we recommend a minimum of 1 to $1.5 \mathrm{hr}$ contact time to ensure disinfection and vapour clearance. If the room is opened at an early time following disinfection, the residual vapors of $\mathrm{H}_{2} \mathrm{O}_{2}$ may cause irritation and discomfort in eyes. 
6) The machine should be cleaned at the end of the day as per the manufacturer's instruction. Usually, a 10 min cycle with distilled water may be used, for machine nozzle cleaning and avoid any clogging.

\section{Step 6: Post-disinfection procedures}

\section{Step 6.1: Collection of exposed biological indicators and disinfected PPE}

1) The worker must wear an appropriate PPE gear (Table 1) and enter the room via the "clean area" (Fig. 8a).

2) After entry, the HCW must FIRST collect the exposed biological indicators in respective media tubes (Fig. 8b) for testing for quality assurance.

Note: The biological indicator spore strips will be collected in a tube pre-filled with 5-6 $\mathrm{ml}$ of brain heart infusion broth or tryptic soy broth. The tubes are properly sealed, packed in a polythene bag, wiped clean with $0.5 \%$ hypochlorite and pass over one-by-one to a HCW standing in the "clean area" outside the room (Fig. 9a). These tubes will be transported by the HCW to a dedicated culture room with an incubator to test for quality assurance.

3) After transferring the control strips outside the room, the disinfected PPE will be collected, packed in bags, and bags will be labeled with disinfection cycle number and date (on the front). The bags should be wiped with $0.5 \%$ sodium hypochlorite prior to handing over to the second HCW standing in the clean area.

4) These disinfected bags should be kept in a dedicated area and MUST NOT be opened until the test results of indicators confirms a successful disinfection (Step 6.2). If for some reason the disinfection process does not work, the bags of the corresponding run should be taken back to the disinfection room and would be processed like other used PPE (Step 4).

5) After handing over the disinfected PPE, the worker may continue to work or prepare for next cycle, or else may move to doffing area, change and exit the facility.

\section{Step 6.2: Quality assurance of a disinfection cycle}

6) After transport of the indicator tubes to the culture facility, these will be incubated at $55^{\circ} \mathrm{C}$ for $3-5$ days under shaking conditions (180 rpm) as per the manufacturer's instructions. This is required to determine the growth or recovery of biological indicators that were exposed in a given disinfection cycle.

7) Change in turbidity is considered as a measure of growth; and an absence of growth indicates a successful sterilization cycle (Fig. 10). If doing CFU, a difference of a minimum of 3 log (i.e. more than 99.9\% between positive control and disinfected biological indicator) may be considered a successful run. 


\section{Step 7: Post-disinfection quality check of PPE for reuse}

Once the successful disinfection is established (no growth in spores kept in media till 72 hours, Fig. 10), the bags will be transferred to the post-disinfection processing area.

1) The bags will be opened here and the disinfected PPE bags may be looked for small spots/stains etc., and can be cleaned with $70 \%$ ethanol or $0.1 \%$ hypochlorite or any other cleaning agent as quality check (Fig. 11).

2) If any torn PPE or N-95 masks are observed, it should be discarded at this step.

3) Once the post-disinfection Quality check is complete, the decontaminated PPE may be packed and can be distributed as per the requirement.

Note:

a. The disinfection protocol is valid for N-95 masks, glasses and goggles, and hence can be used to develop a single reprocessing site for all the used PPE.

b. Disinfected PPE including coverall and masks should be checked for physical integrity.

c. The number of disinfection cycles undergone by a particular PPE item is also dependent on the quality of PPE item used and efforts must be made to ensure that no deformity exist in the PPE.

d. Appropriate biological indicator should be used in the room for each cycle for quality control. If room is big (>2000 cu ft., two biological indicators may be used, one each at the both ends of the room.

e. A proper cataloguing of disinfected PPE may be considered during recirculation to ensure tracking of the number of disinfection cycles undergone by the PPE item.

\section{Troubleshooting}

\section{Time Taken}

\section{Anticipated Results}

\section{SUMMARY}

The experience of on-going pandemic has highlighted the pressures on supplies of PPE globally. Decontamination of PPE can be posited as the key solution to alleviate the pressure of PPE shortage in 
emergency situations while also resolving the problem of excess biomedical waste. Using the presented SOP as a guide, we have been able to successfully operationalize a VHP-based PPE disinfection facility at our Institute and have been able to recycle significant volumes of PPE for reuse as per requirements (Saini et al., 2020).

Our detailed step-by-step illustrative guide presented here aims to provide an in-depth standard operating guideline to allow a safe establishment and operation of a PPE disinfection Facility. As per CDC COVID19 report, 2020, disinfection methods including ultraviolent germicidal irradiation (UVGI), moist heat and vaporized hydrogen peroxide (VHP) may be used as effective PPE disinfection methods. The guidelines presented here are framed with a considerate view of general biosafety and are independent of the disinfection methodology that a healthcare centre or any research centre may choose to operationalize. Also, there is an immediate need to encourage regulatory body-supported research to endorse the routine decontamination of PPE to ensure access and availability of PPE. We strongly believe that establishment of similar economically viable and environmentally sustainable disinfection facilities may be instrumental in alleviating global PPE shortages in various healthcare settings, especially in pandemic situations such as COVID-19.

\section{Tables}

Due to technical limitations, Tables 1-2 can be found in the Supplemental files section.

\section{References}

1. Bergman, M., Viscusi, D.J., Heimbuch, B.K. et al. Evaluation of Multiple (3-Cycle) Decontamination Processing for Filtering Facepiece Respirators. J. Eng. Fiber. Fabr. 5(4), 33-41 (2010).

2. CDC COVID-19 report. Decontamination and Reuse of Filtering Facepiece Respirators (2020); Available from: https://www.cdc.gov/coronavirus/2019-ncov/hcp/ppe-strategy/decontamination-reuserespirators.html

3. Heimbuch, B.K., Wallace, W.H., Kinney, K., et al. A pandemic influenza preparedness study: use of energetic methods to decontaminate filtering facepiece respirators contaminated with H1N1 aerosols and droplets. Am. J. Infect. Control. 39(1), e1 - e9. (2011).

4. Kampf, G., Todt, D., Pfaender, S., \& Steinmann, E. Persistence of coronaviruses on inanimate surfaces and their inactivation with biocidal agents. J. Hosp. Infect. 104, 246-251 (2020).

5. OSHA. Pandemic Influenza Preparedness and Response Guidance for Healthcare Workers and Healthcare Employers (2007). 
6. Polkinghorne, A. \& Branley J. Evidence for decontamination of single-use filtering facepiece respirators. J. Hosp. Infect. (ahead of print) (2020).

7. Rutala, W.A. \& Weber D.J. Guideline for disinfection and sterilization in healthcare facilities (2008). Available from: https://www.cdc.gov/infectioncontrol/guidelines/ disinfection/.

8. Saini, V., Sikri, K., Batra, S.D., Kalra, P. \& Gautam, K. Development of a highly effective low-cost vaporized hydrogen peroxide-based method for disinfection of personal protective equipment for their selective reuse during pandemics. Gut Pathog. 12, 29 (2020).

9. Viscusi, D.J., Bergman, M.S., Eimer, B.C. \& Shaffer, R.E. Evaluation of five decontamination methods for filtering facepiece respirators. Ann. Occup. Hyg. 53(8), 815 - 827 (2009).

\section{Acknowledgements}

We thank Prof. Randeep Guleria (Director, AlIMS New Delhi) for motivating us to develop these guidelines. We would further like to thank Prof. Chitra Sarkar (Dean Research, AlIMS, New Delhi), Prof. Subrata Sinha (Dean Exams, AllMS and Coordinator BSL-3 facilities, CCRF AIIMS) and Prof. Shyam Chauhan (Head, Department of Biotechnology) for their consistent support and encouragement.

\section{Figures}


Step 1: Segregation of recyclable Used

PPE by the user at site

Step 2: Collection, packaging and transport

of Used PPE to Disinfection Facility
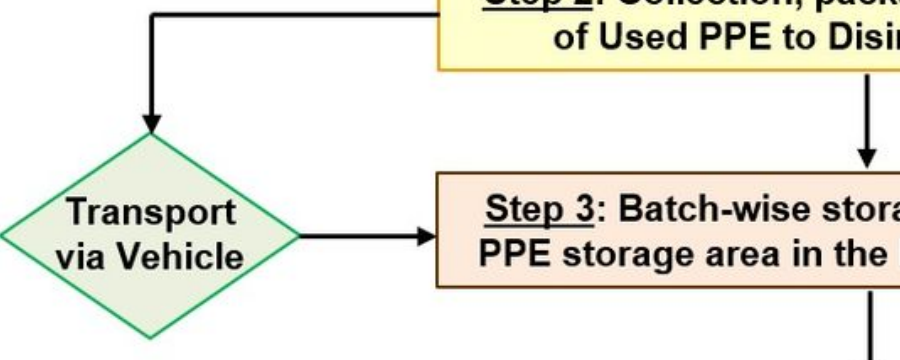

Step 3: Batch-wise storage of bags at Used

PPE storage area in the Disinfection Facility

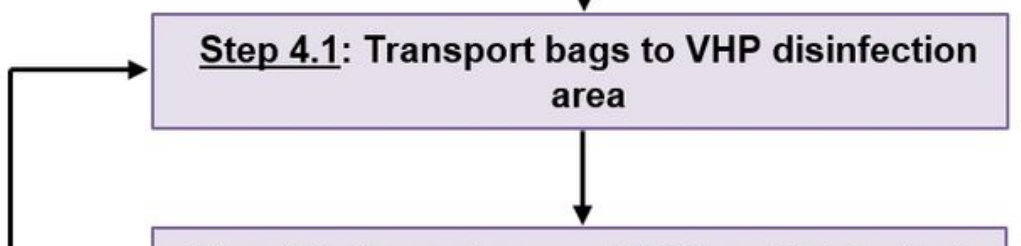

Step 4.2: Arranging used PPE and biological indicators in disinfection room

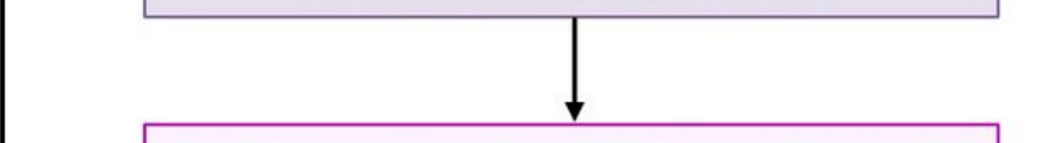

Step 5: Running of the VHP based disinfection cycle

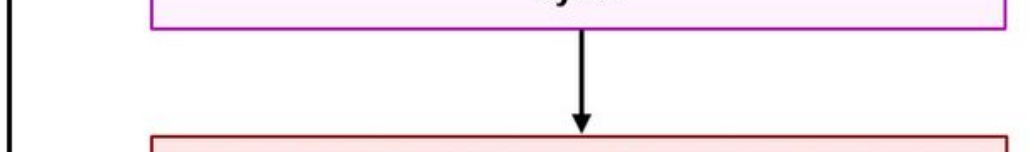

Step 6.1: Enter room $1.5 \mathrm{hrs}$ post-VHP run, collect indicators and disinfected PPE

\section{Figure 1}

Overview of the workflow to operationalize a PPE Disinfection Facility. 
(a) For Disposal

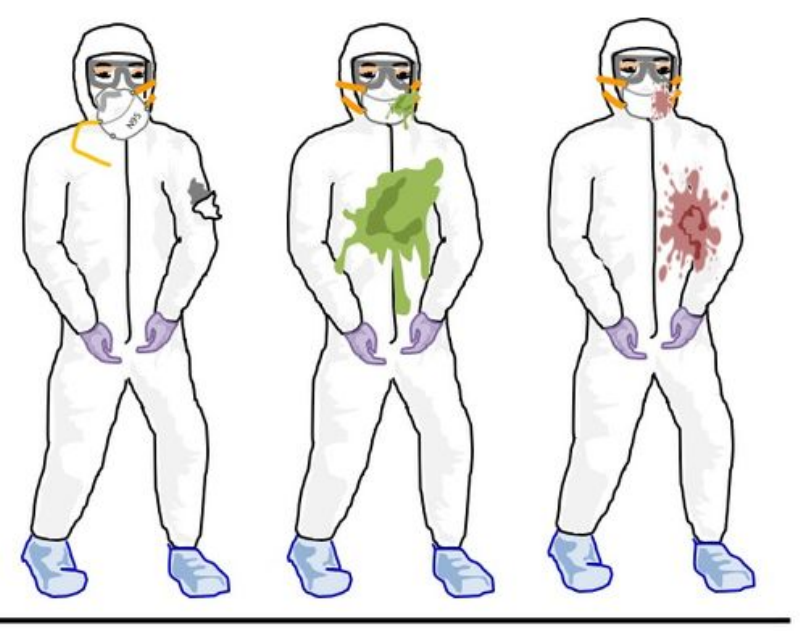

Unsuitable for recycling

(PPE heavily soiled, torn or masks with broken elastic)

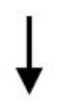

Discard as per Institutional guidelines (b) For Disinfection

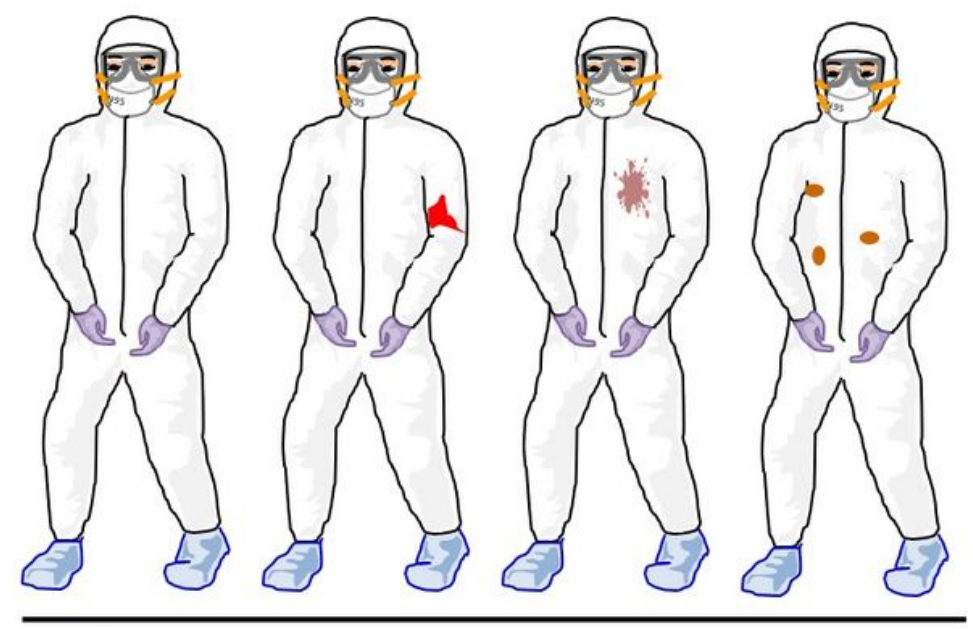

Doffed PPE with no tear, intact elastic or minor stain are suitable for recycling

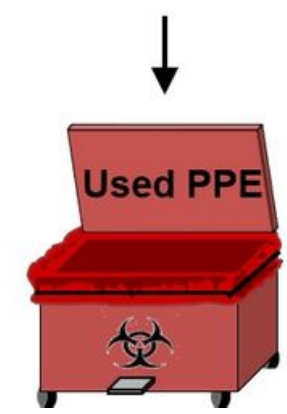

Figure 2

Segregation of used PPE by the user at the doffing site for (a) discard or (b) disinfection. 
Collection of recyclable PPE

(Fig. 2b)
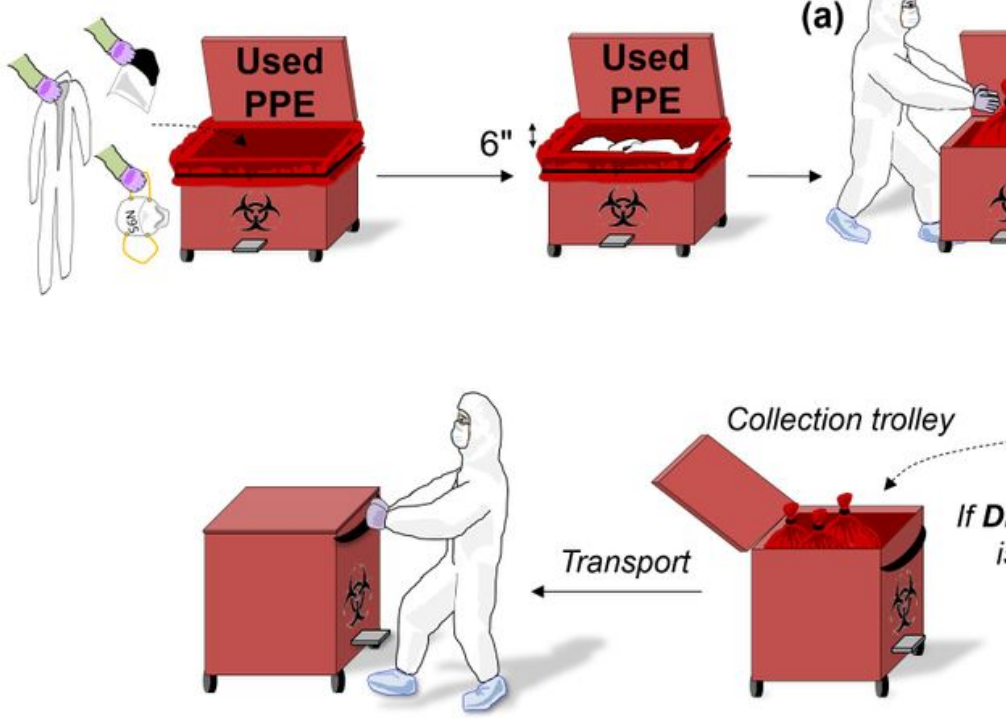

(d)
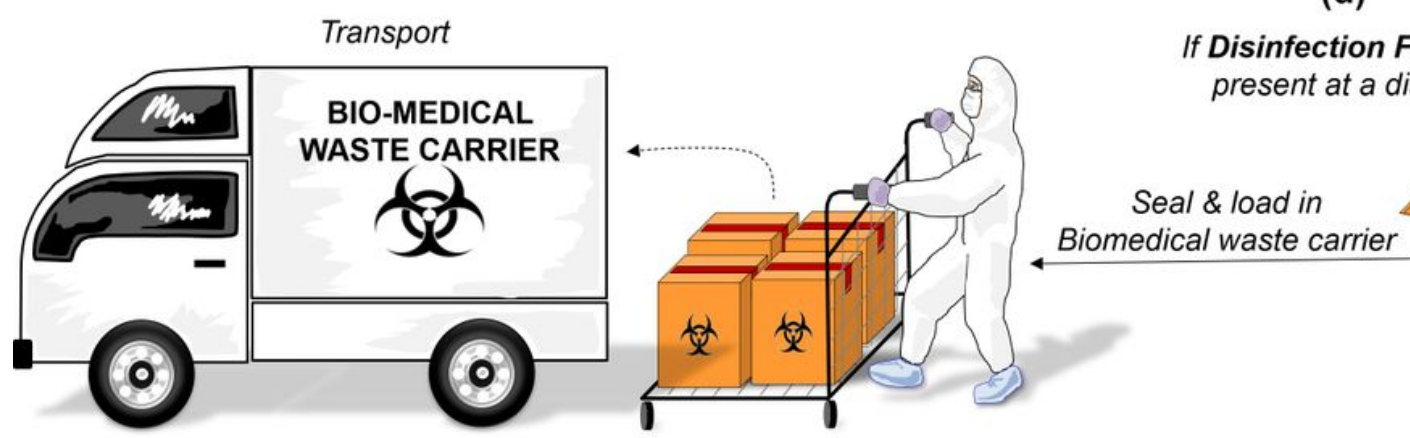

(c)

is present nearby

OR

(d)
Double bag

$\checkmark$

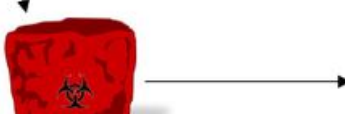
hypochlorite

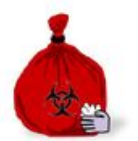

(b)

PPE gear

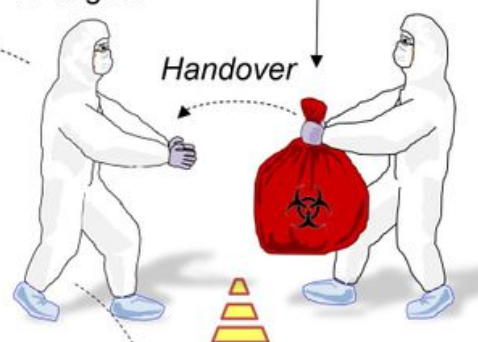

Line I

Door

$$
\text { distance }
$$

\section{Figure 3}

Collection and transport of the recyclable PPE containing bags, to the Disinfection Facility. 


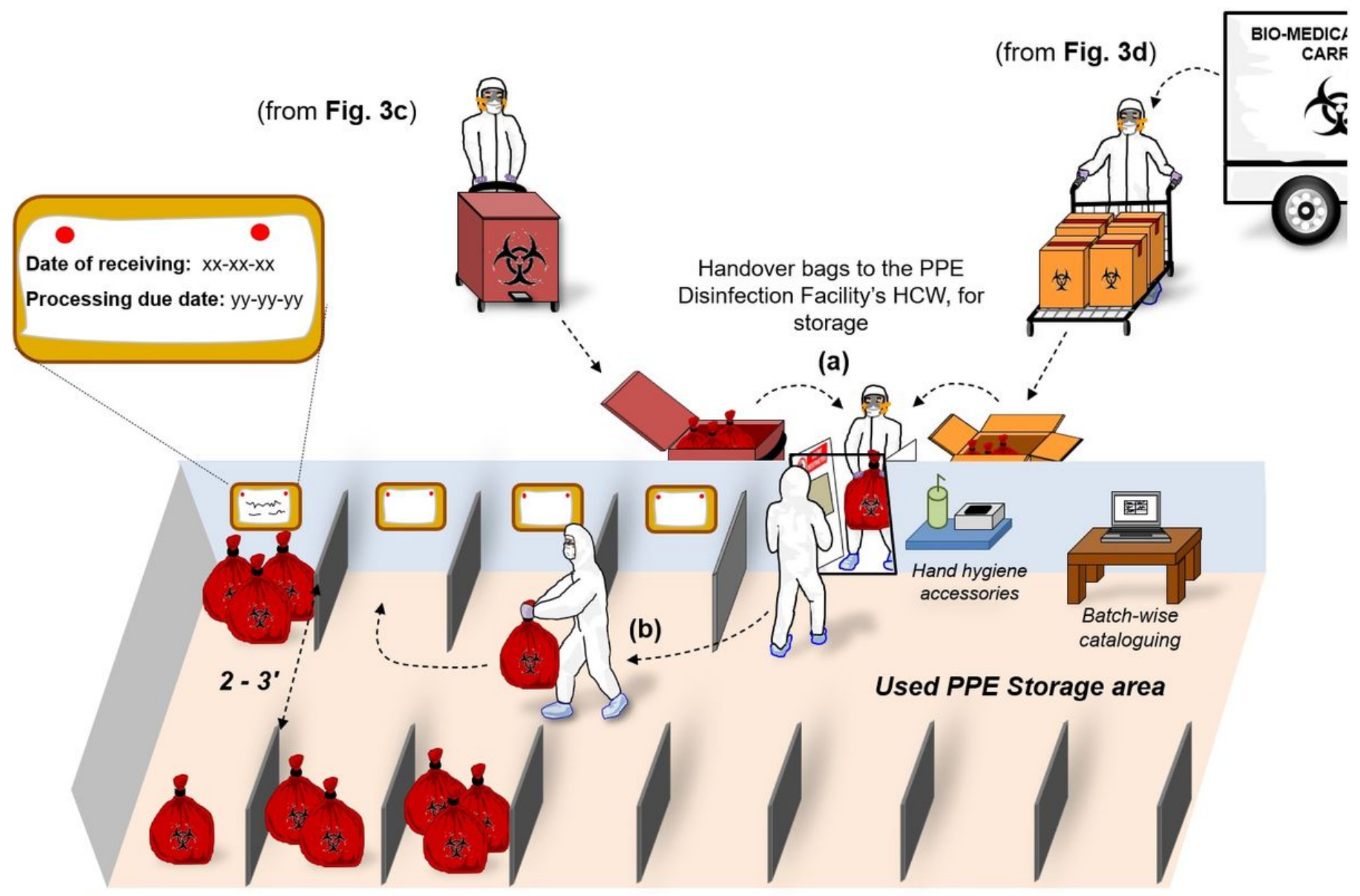

- Store bags for 4-6 days to reduce viral load

- Ensure proper cataloguing of the date of receiving \& due date of processing of the used PPE!

Figure 4

Storage of Used PPE at the Storage area of the Disinfection facility. 


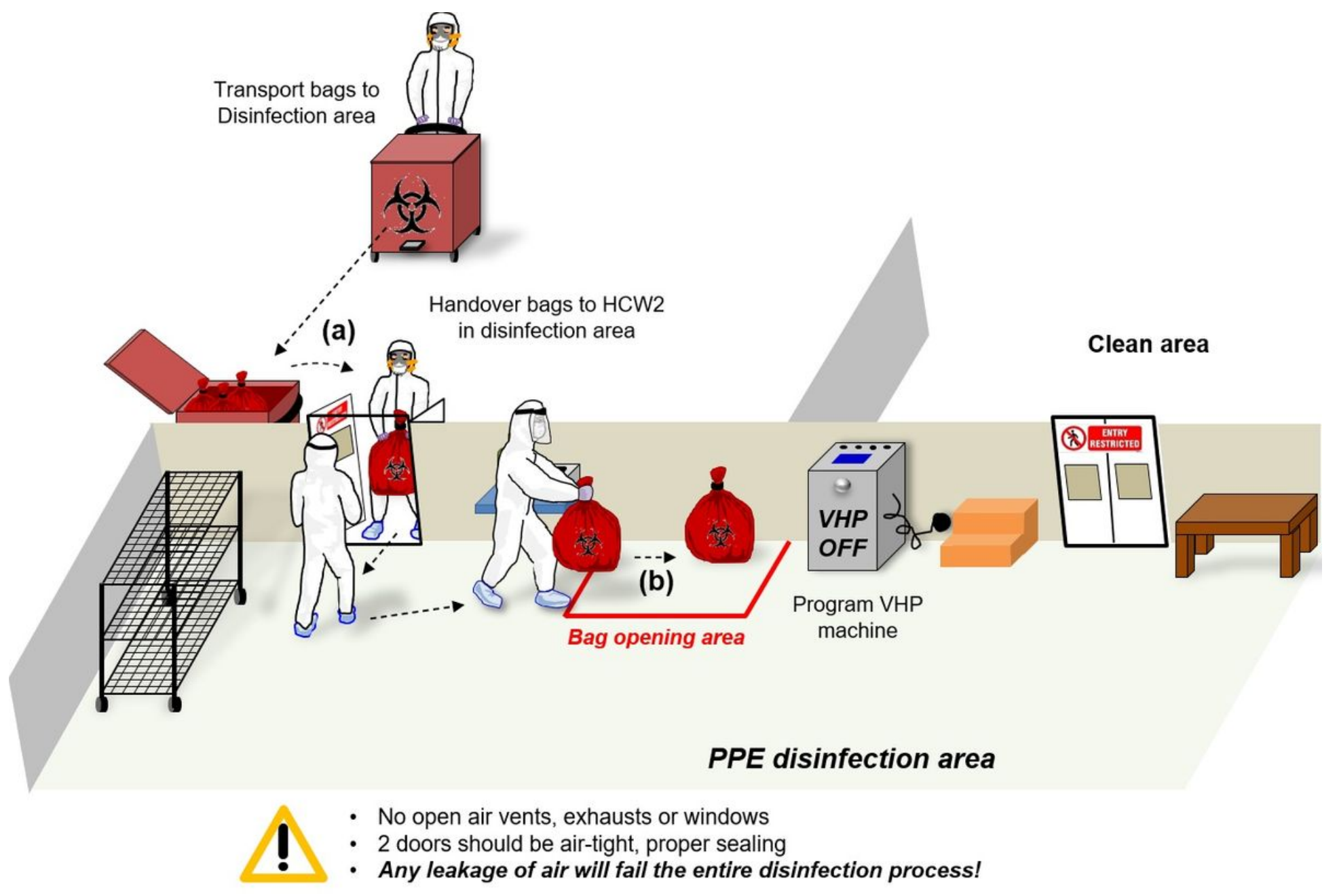

Figure 5

Transport of Used PPE bags from the storage area to the Disinfection area. 


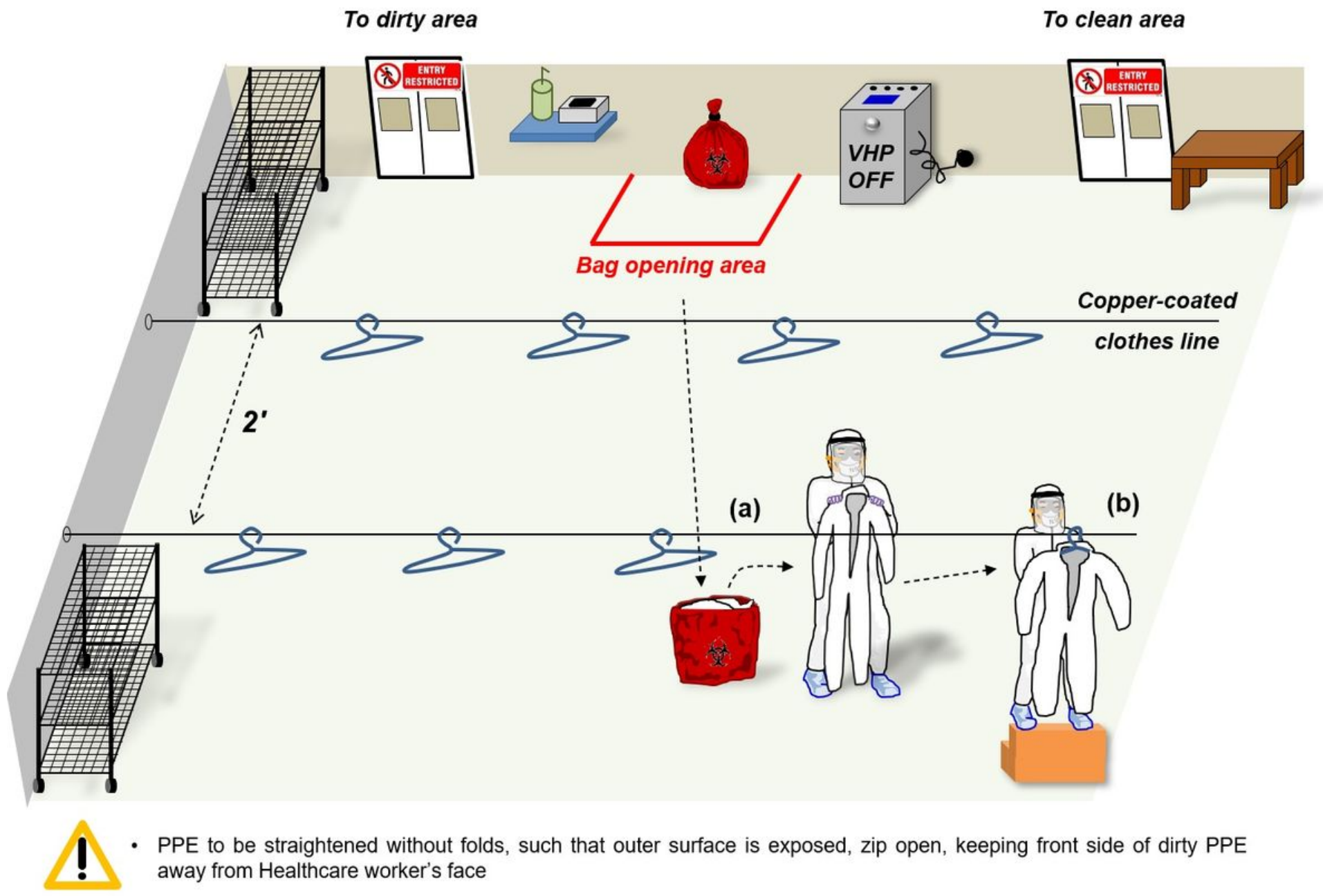

Figure 6

Arrangement of used PPE in disinfection area. 


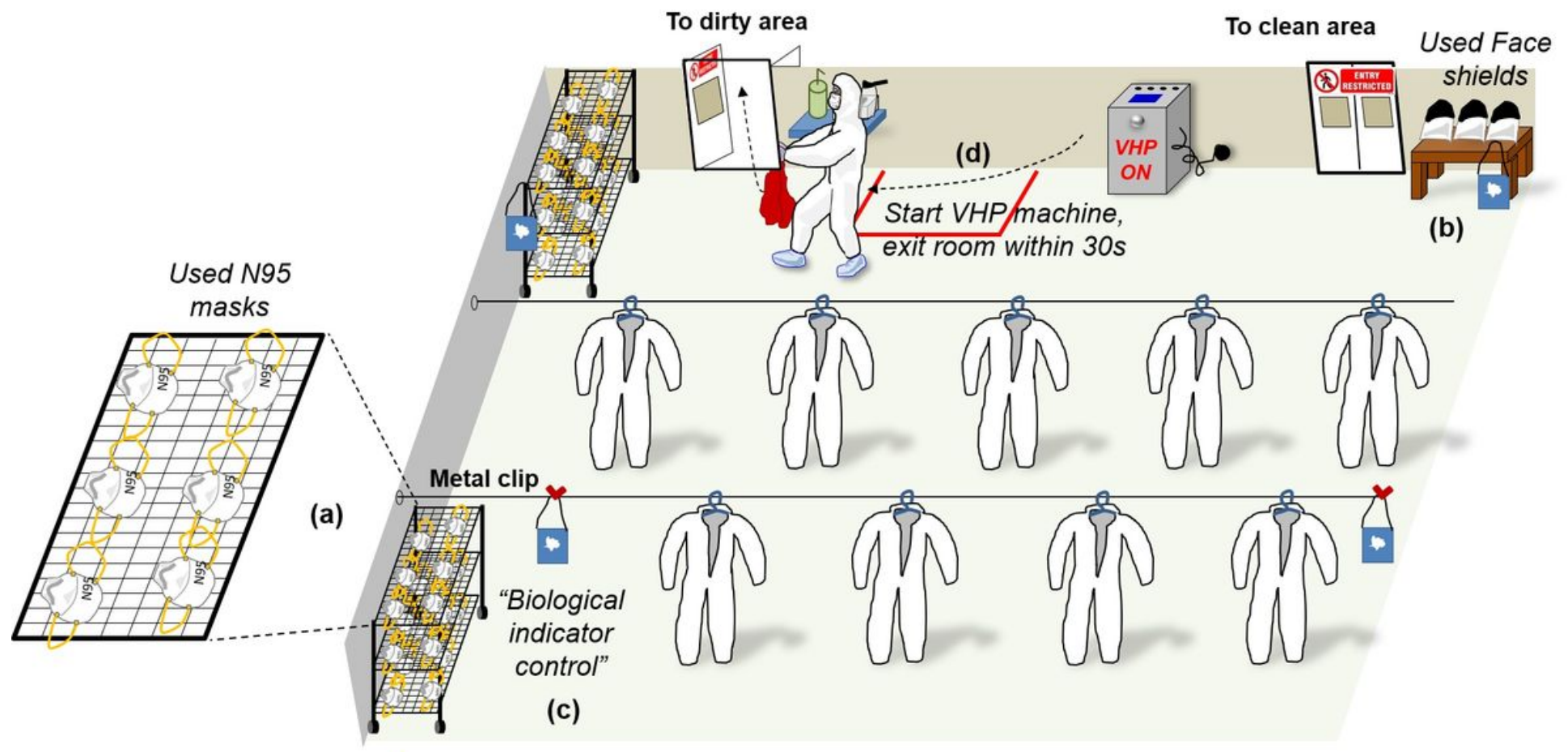

\section{Peroxide vapors start after an automatic 30 second delay, allowing HCW to exit the room, and
seal the door from outside.}

\section{Figure 7}

Alignment of used PPE items (coveralls, N-95 masks, face shields) and biological indicators in the Disinfection area, prior to initiation of the disinfection cycle. 


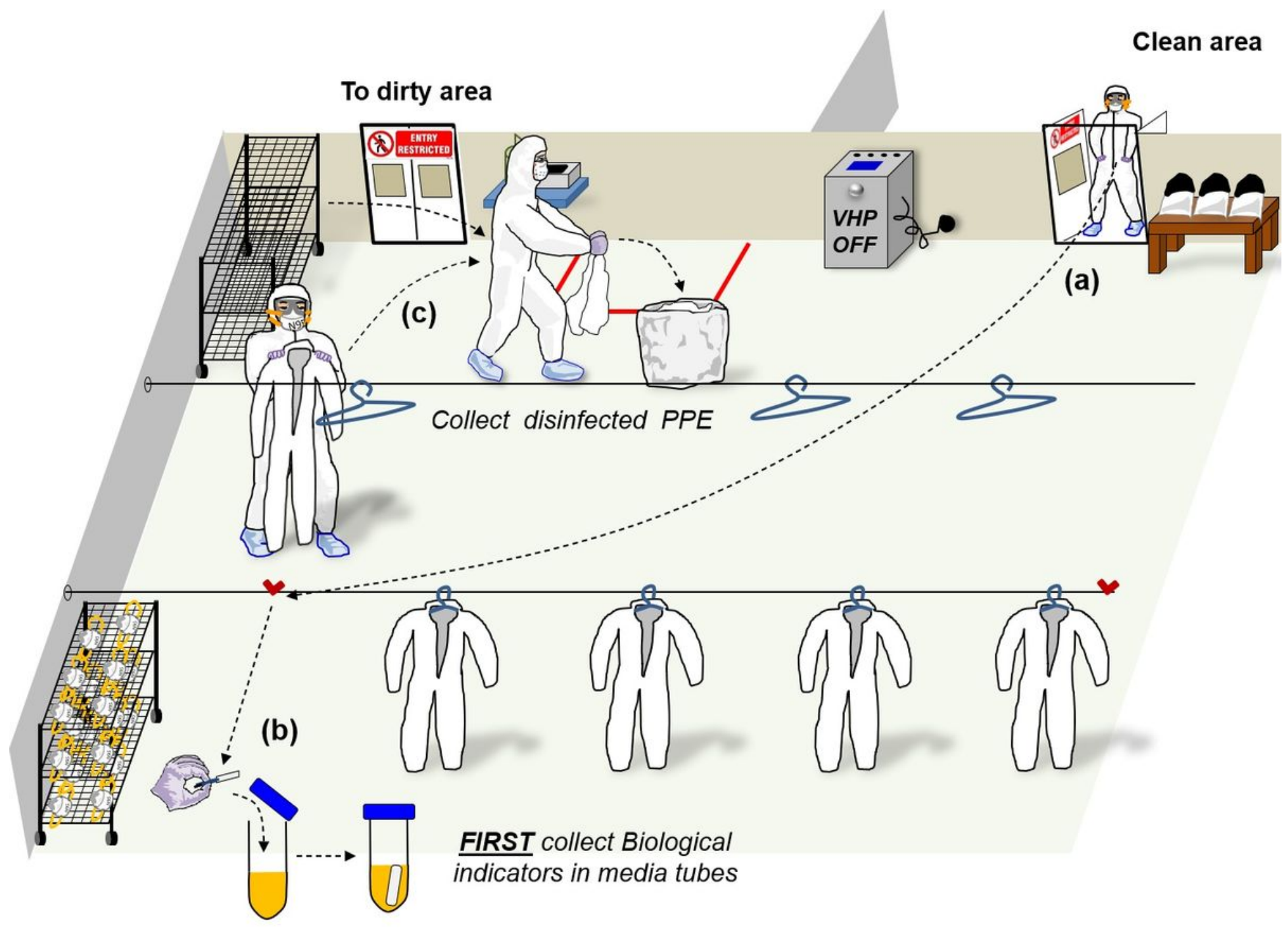

- HCW must enter room in PPE gear, even post-disinfection, until quality assurance is confirmed.

- First, exposed biological indicators should be removed and put in culture media. Thereafter the disinfected PPE should be collected.

\section{Figure 8}

Post-disinfection, collection of exposed Biological indicators $(a, b)$, followed by the collection of disinfected PPE items (c). 
(a) Transport indicator tubes to culture facility for testing quality assurance

(b) Transport labelled bags to clean storage area
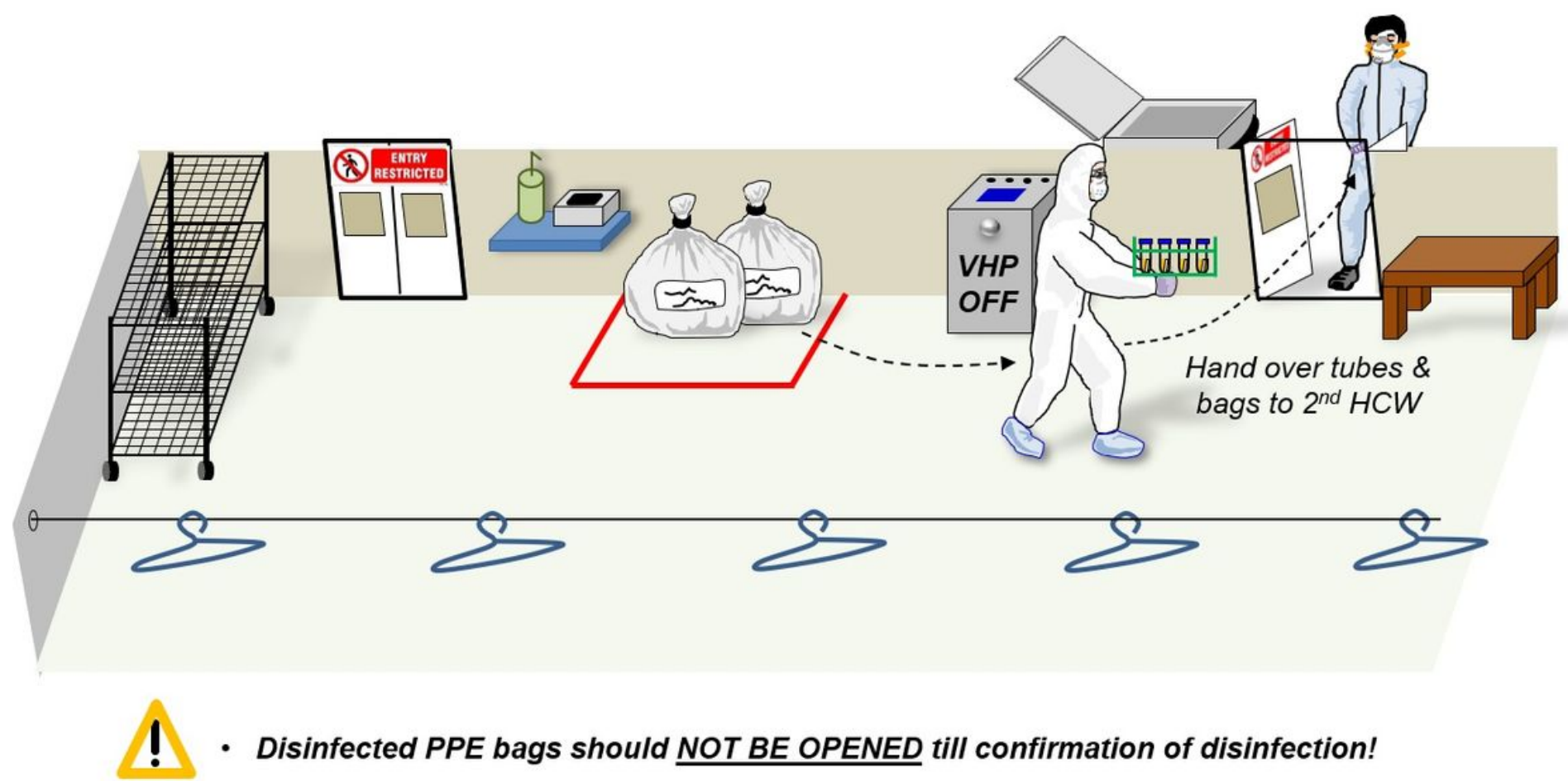

\section{Figure 9}

Handing over (a) the exposed Biological indicators and (b) the disinfected PPE containing bags, to the healthcare personnel in the clean area. 
Biological indicator (eg): Bacillus stearothermophilus spores

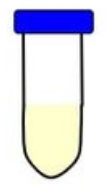

Media

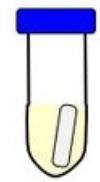

Media

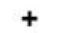

Untreated

spores

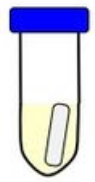

Media

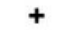

spores

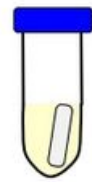

Media

reated 2

spores

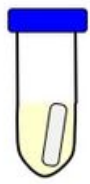

Media

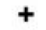

Treated 3

spores

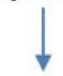

Incubate at $55^{\circ} \mathrm{C}, 180 \mathrm{rpm}$ for $\mathbf{4}-\mathbf{6}$ days

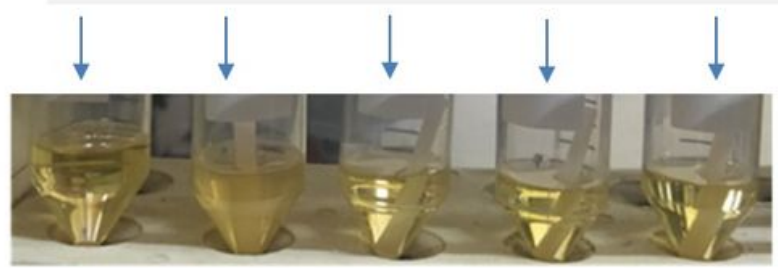

\begin{tabular}{|c|c|c|c|c|c|}
\cline { 2 - 6 } \multicolumn{1}{c|}{} & $\begin{array}{c}\text { Negative } \\
\text { Control }\end{array}$ & $\begin{array}{c}\text { Positive } \\
\text { Control }\end{array}$ & \multicolumn{3}{c|}{$\begin{array}{c}\text { Test } \\
\text { (VHP treated) }\end{array}$} \\
\cline { 2 - 6 } & $\begin{array}{c}\text { Media } \\
\text { Control }\end{array}$ & Untreated & Test 1 & Test 2 & Test 3 \\
\hline $\begin{array}{c}\text { Expected } \\
\text { growth }\end{array}$ & - & + & - & - & - \\
\hline
\end{tabular}

\section{Repeat} disinfection of entire batch

(Fig. 5)
No growth

in Test<smiles>C1=C[CH-]CC=C1</smiles>

Disinfection of particular batch confirmed!

Figure 10

Testing quality assurance of a disinfection cycle, by assessing growth recovery of the exposed biological indicators.

(b)

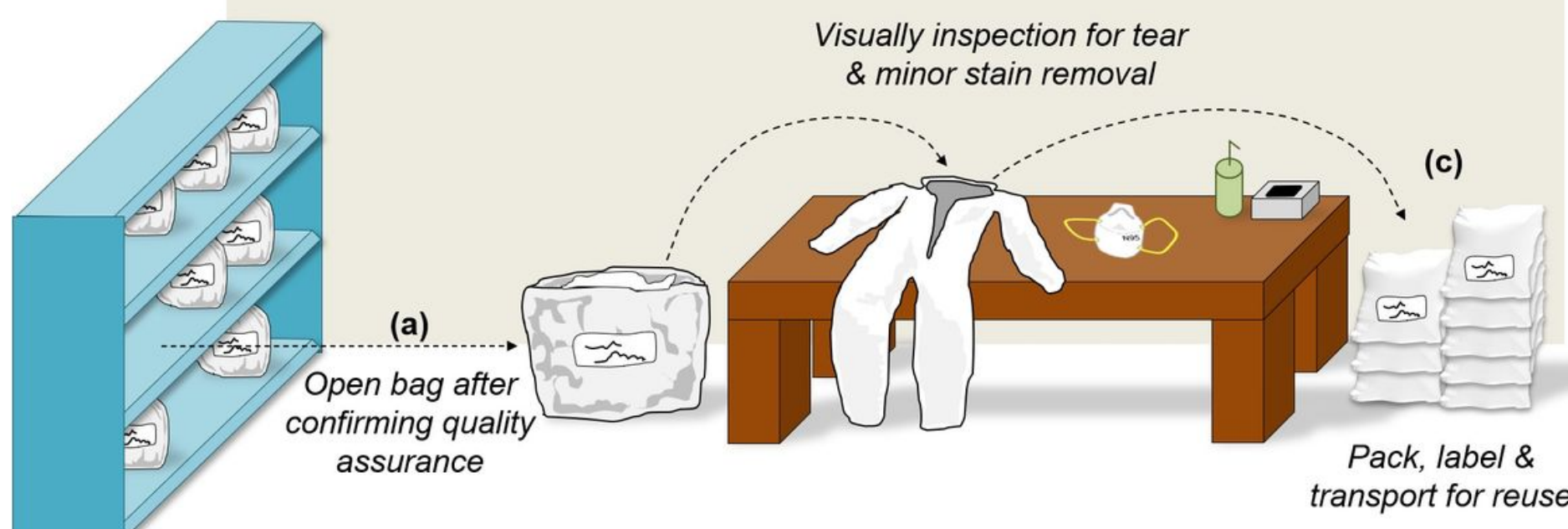

Figure 11

Post disinfection visual inspection of individual PPE items, for storage or immediate reuse. 


\section{Supplementary Files}

This is a list of supplementary files associated with this preprint. Click to download.

- Table1.jpg

- Table2.jpg 